\title{
The neuroprotective effects and possible mechanism of action of a methanol extract from Asparagus cochinchinensis: in vitro and in vivo studies.
}

\author{
Aldarmaa Jalsrai ${ }^{1,3}$, Tadahiro Numakawa ${ }^{3}$, Hiroshi Kunugi ${ }^{3}$, Daniela Dieterich ${ }^{2}$, Axel Becker $^{2}$. \\ ${ }^{1}$ Institute of Traditional Medicine and Technology, Ministry of Education, Culture, and Science, \\ Ulaanbaatar, Mongolia
}

${ }^{2}$ Otto von Guericke University, Faculty of Medicine, Institute of Pharmacology and Toxicology, Leipziger Strasse 44, 39120 Magdeburg, Germany

\footnotetext{
${ }^{3}$ Department of Mental Disorder Research, National Institute of Neuroscience, National Center of Neurology and Psychiatry, Tokyo, Japan
}

\footnotetext{
*Corresponding author: Axel Becker, Otto von Guericke University, Faculty of Medicine, Institute of Pharmacology and Toxicology, Leipziger Strasse 44, 39120 Magdeburg, Germany

Phone: $\quad++493916715351$

Fax: $\quad++4939167290149$

E-mail: axel.becker@med.ovgu.de
} 
Abstract

Extracts of Asparagus cochinchinensis (AC) have antitumor, anti-inflammatory, and immunostimulant effects. The neurobiological mechanisms underlying the effects of AC have not been sufficiently explored. Thus we performed in vivo and in vitro experiments to further characterize potential therapeutic effects and to clarify the underlying mechanisms.

In the tail suspension test immobility time was significantly reduced after administration of AC which suggests antidepressant-like activity without effect on body core temperature. Moreover, in animals pretreated with $\mathrm{AC}$ infarct size after occlusion of the middle cerebral artery was reduced. In vitro experiments confirmed neuroprotective effects. Total saponin obtained from AC significantly inhibited $\mathrm{H}_{2} \mathrm{O}_{2}$-induced cell death in cultured cortical neurons. The survivalpromoting effect by AC saponins was partially blocked by inhibitors for extracellular signalregulated kinase (ErK) and phosphoinositide 3-kinase Akt (PI3K/Akt) cascades, both of which are known as survival-promoting signaling molecules. Furthermore, phosphorylation of Scr homology-2 (SH2) domain-containing phosphatase 2 (Shp-2) was induced by AC, and the protective effect of AC was abolished by NSC87877, an inhibitor for Shp-2, suggesting an involvement of Shp-2 mediated intracellular signaling in AC saponins. Moreover, AC-induced activation of pShp-2 and ErK1/2 were blocked by NSC87877 indicating that activation of these signaling pathways was mediated by the Shp-2 signaling pathway.

These effects appear to be associated with activation of the Shp-2, ErK1/2 and Akt signaling pathways. Our results suggest that AC has antidepressant-like and neuroprotective (reducing infarct size) effects and that activation of $\mathrm{pShp}-2$ and $\mathrm{pErK} 1 / 2$ pathways may be involved in the effects. 
Highlights

- Asparagus cochinchinensis extract (AC) exerts neuroprotective effects

- AC exerts antidepressive-like effects and reduces infarct size

- $\mathrm{AC}$ activates $\mathrm{pErK} 1 / 2$ and pAkt pathways

Keywords: Asparagus cochinchinensis, saponin, ErK/Shp-2, neuroprotection,

\begin{abstract}
Abbreviations
Asparagus cochinchinensis, AC; body core temperature, BCT; basic fibroblast growth factor, bFGF; Brain-derived neurotrophic factor BDNF; extracellular signal-related kinase, ErK; days in vitro, DIV; glucocorticoid receptor, GR; imipramine Imi; middle cerebral artery occlusion, MCAO; mineralocorticoid receptor, MR; 3-(4,5-dimethylthiazol-2-yl)-2,5-diphenyltetrazolium bromide, MTT; mitogen-activated protein kinase/extracellular signal-regulated protein; MAPK/ErK; phosphatidylinositol 3-kinase, PI3K; Reactive Oxygen Species, ROS; Tail suspension test, TST; Thin layer chromatography, TLC;
\end{abstract}




\section{Introduction}

Growing evidence demonstrates that neuroprotective mechanisms are pivotal in the pathophysiology of neurodegenerative and psychiatric disorders (Kölsch and Rao, 2002; Abel and Zukin, 2008; Hunsberger et al., 2009). Schizophrenia and depression are said to be diseases characterized by both neurodevelopmental and neurodegenerative components in conjunction with progressive inflammation processes (Lieberman, 1999; Maes et al., 2009). The complex mechanisms underlying neurodegeneration are still not fully understood. Oxidative stress has been implicated as one component (Alexi et al., 2000; $\mathrm{Ng}$ et al., 2008; Michel et al., 2012), inducing protein oxidation, lipid peroxidation, and DNA oxidation. Moreover, oxidative stress is closely associated with secondary cell death in many disorders of the central nervous system including stroke (Majid, 2014; Pantcheva et al., 2014). Consequently, antioxidant strategies have been proposed as a therapy for experimental ischemic stroke. However, clinical trials have not yet been able to promote the adoption of such strategies in patient treatment regimens. It has been maintained that the complexity of the ischemic cascade pathways with their different temporal profiles indicate the adoption of a strategy based on neuroprotective agents with multiple mechanisms of action, rather than a single-target 'magic bullet' strategy (Moretti et al., 2014).

The attributes of many herbs, including species of Asparagus (Asparagaceae), have received much attention, because they are reported to have neuroprotective (Xiong et al., 2011), antiinflammatory, anti-amnestic (Ojha et al., 2010), antipsychotic (Zhang, 2004), and antidepressant effects (Singh et al., 2009). Asparagus cochinchinensis (AC) Merill is well known as a tonic and anti-inflammatory (Kim et al., 1998; Park et al., 2011) herbal medicine in Asian countries. Pharmacological studies of AC have demonstrated its antitumor (Park et al., 2011), antiinflammatory (Lee et al., 2009), and immunostimulant activities (Xiong et al., 2011). Steroidal saponins and sapogenins are the major active components of Asparagus species. The roots of this plant contain mainly asparagosides, furostanol oligosides, asparacosin, and sarsasaponen (Konishi and Shoji, 1979; Yang et al., 2002; Zhang et al., 2004). Sarsasapogenin has been isolated from 
such Asparagus species as A. officinals, A. curillus, A. cochinchinensis, and A. racemosus (Zhang et al., 2004; Chawla et al., 2011; Negi et al., 2011). It has been reported that furostanol oligosides from AC consist of sarsasapogenins and monosaccharides (Konishi and Shoji, 1979).

In spite of its popular use and many potential interesting properties for clinical use, the neurobiological mechanisms underlying the effects of AC have not been sufficiently explored. There is very limited scientific evidence about the potential neuroprotective effects of this plant. Thus in the current study, our initial aim was to clarify possible neuroprotective actions of a methanol extract of $\mathrm{AC}$ on $\mathrm{H}_{2} \mathrm{O}_{2}$-induced neurotoxicity in cultured cortical neurons. $\mathrm{H}_{2} \mathrm{O}_{2}$ is the stable form of Reactive Oxygen Species (ROS), and causes cell death (Halliwell et al., 1992; Halliwell, 1992a; Halliwell, 1992b). Moreover, we sought to determine the neurobiological mechanisms of action of AC. Using in vivo models, we further investigated possible antidepressant-like and neuroprotective effects using the tail suspension test and a stroke model (permanent occlusion of the middle cerebral artery).

\section{Experimental procedures}

\subsection{Plant material}

Roots of AC were provided by the Institute of Traditional Medicine and Technology Mongolia, and were identified by comparison with a standard sample preserved at the Herbal Institute of Botany, Mongolian Academy of Science.

\subsection{Isolation of the methanol extract from Asparagus cochinchinensis}

AC saponin was extracted according to the method proposed by Konishi and Shoji (1979). Two $\mathrm{kg}$ of dried powder of AC root was macerated in methanol (10:1) for 5 days. The extract was filtered and concentrated. The yield of extract was $185 \mathrm{~g}(9.25 \% \mathrm{w} / \mathrm{w})$. The residue was dissolved 
in water and partitioned with petroleum ether and a mixture solvent of ethyl acetate and n-butanol $(5: 1 \mathrm{v} / \mathrm{v})$ with increasing polarity. Petroleum ether and ethyl acetate-n-butanol (5:1) soluble fractions were discarded. The aqueous layer fraction was evaporated to dryness under vacuum to obtain a brown powder $(114 \mathrm{~g})$, and stored in a refrigerator at $-35^{\circ} \mathrm{C}$ until further use. This brown powder is referred to as the total saponins of AC. Using this preparation of AC, Koniski and Shoji (1979) established the presence of furostanol oligosides which consist of sarsasapogenin and

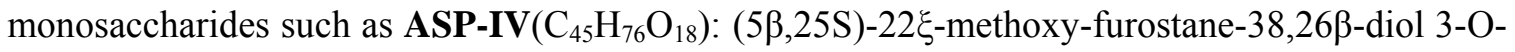
[ $\beta$-D-xyloppyranosyl-( $1 \rightarrow 4)-\beta$-D-glucopyranoside]-26-O- $\beta$-D-glucopyranoside; Mol wt: 904; ASP-V $\left(\mathrm{C}_{46} \mathrm{H}_{78} \mathrm{O}_{18}\right): \quad(58,26 \mathrm{~S})-22 \xi-M e t h o x y-f u r o s t a n e-38,26-d i o l \quad 3-\mathrm{O}-[\alpha-\mathrm{L}-$-rhamnopyranosyl$(1 \rightarrow 6)-8$-D-glucopyranoside]-26-O-8-D-glucopyramoside; Mol wt: 918; ASP-VI $\left(\mathrm{C}_{51} \mathrm{H}_{86} \mathrm{O}_{22}\right)$ :

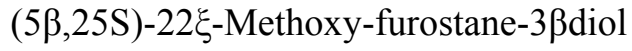

3-O-[ $\beta$-D-xylopyranosyl- $(1 \rightarrow 4)-[\alpha-\mathrm{L}-$

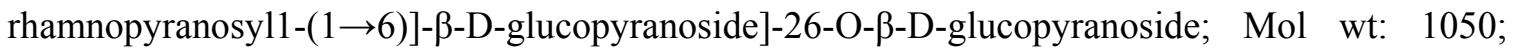
ASP-VII $\left(\mathrm{C}_{57} \mathrm{H}_{96} \mathrm{O}_{27}\right):(5 \beta, 25 \mathrm{~S})-22 \xi$-Methoxyfurostane-3 $\beta, 26$-diol 3-O-D-glucopyranosyl-(1 $\left.\rightarrow 2\right)$ $[\beta$-D-xylopyranoxsyl- $(1 \rightarrow 4)]$-[ $\alpha$-L-rhamnopyranosyl- $(1 \rightarrow 6)-\beta$-D-glucopyranoside]-26-O- $\beta$-Dglucopyranoside; Mol wt: 1212. Therefore, we assumed that the average molecular weight of saponins obtained from AC was 1021. During the experiments, methanol extracts of AC were dissolved in distilled water. We used the following AC concentrations: $10 ; 100 ; 500 ; 1000 \mathrm{mg} / \mathrm{ml}$ or $0.00987 ; 0.0987 ; 0.49 ; 0.987 \mathrm{mM}$.

\subsection{Standardization of extract}

The methanolic extract of AC was standardized for the total saponin content as follows. The extract $(1 \mathrm{~g})$ was defatted with petroleum ether $\left(60^{\circ}-80^{\circ} \mathrm{C}\right)$. The aqueous fraction was extracted with n-butanol saturated with water, and the butanol soluble fraction was concentrated to obtain a brown powder $(0.33 \mathrm{~g})$, which was partitioned between water and ethyl acetate-butanol (5:1). The ethyl acetate-n butanol soluble fraction was discarded. The residue fraction was dried to a constant weight of $0.2 \mathrm{~g}$ at $105^{\circ} \mathrm{C}$. 
Total saponin was found at a concentration of $60.2 \%$. The standard contains $0.25 \mathrm{mg}$ APS VI in $1 \mathrm{ml}$ methanol. Thin layer chromatography (TLC) of the butanol extract revealed the presence of the four major spots, namely AspIV-VII. Solvent system: chloroform-methanol-water (7:3:0.4). Their structures (Fig. 1) were characterized by comparing their physical and spectral data with values in the literature (Konishi and Shoji, 1979).

\subsection{Cell culture}

Time-mated pregnant Wistar rats were obtained from SLC8 Labs (Shizuoka, Japan). Primary cortical neurons were prepared as reported previously (Odaka et al., 2014). In brief, whole brains were isolated from postnatal 1-2 day-old rats while anesthetized deeply, and their brains were quickly removed. Obtained cerebral cortices were dissected and treated with papain solution with 200 units $/ \mathrm{ml}$ DNase I for 20 min at $37^{0} \mathrm{C}$. Cells were dissociated by pipetting in culture medium. After cell debris was removed by sterilizing filter (BD Falcon, CA, USA), cortical cells were diluted with culture medium (1:1 mixture of Dulbecco's Modified Eagle's Medium and Ham's F-12 containing 5\% fetal bovine serum (FBS), 5\% horse serum (HS), 18 units $/ \mathrm{ml}$ penicillin, and $18 \mathrm{mg} / \mathrm{ml}$ streptomycin). The dissociated cortical cells were plated at a cell density of $5 \times 10^{5} / \mathrm{cm}^{2}$ on $3.5 \mathrm{~cm}$ dishes (for western blotting), 48-well plates (for MTT [3-(4,5-Dimetylthial-2yl)-2,5-Diphenyltetrazolium Bromide] assay). All dishes or plates were coated with polyethylenimine. To exclude an influence of glial cells in this study, $2 \mu \mathrm{M}$ Cytarabine, a potent inhibitor of glial proliferation was added at day 1 of the in vitro culture (DIV1). 


\subsection{Treatment of the extract and agents}

Cortical cell cultures were incubated with the methanol extracts from AC for 6 hours. The final concentrations of the methanol extracts were $0.01,0.1,0.5$, and $1 \mathrm{mM}$. Dried extract was dissolved in distilled water by $10 \mu \mathrm{l}$ of volume and applied to the cultures. The inhibitors were dissolved in DMSO and applied by $10 \mu$ to the cultures, including U0126 $(10 \mu \mathrm{M})$, LY294002 $(10 \mu \mathrm{M})$, NSC87877 $(50 \mu \mathrm{M})$; they were applied 20 min before adding the dried extract from AC, then the cultures were treated with dried extract from AC in the presence or absence of these inhibitors. After the pre-treatment with dried methanol extract for $6 \mathrm{~h}$, the cultures were exposed to freshly prepared $100 \mu \mathrm{M} \mathrm{H}_{2} \mathrm{O}_{2}$ for $15 \mathrm{~h}$. Prior to $\mathrm{H}_{2} \mathrm{O}_{2}$ exposure, the cell media were replaced with fresh culture medium that did not contain any methanol extract. Fifteen hours after $\mathrm{H}_{2} \mathrm{O}_{2}$ application (DIV3), the media were removed and processed as described below to assess the survival viability of the cortical neurons.

\subsection{MTT assay}

Experiments were performed under sterile condition on DIV3/4 (day 3 MTT, day 4 Western blot analysis) neurons cultured in 48 -well plates. Cell viability was measured using the MTT assay as shown previously (Numakawa et al., 2009). To summarize, the metabolic activity of the mitochondria of surviving cells was estimated by measuring the mitochondrial-dependent conversion of 3-(4,5-dimethylthiazol-2-yl)-2,5-diphenyltetrazoliumbromide (MTT) to blue insoluble formazan salt. Fifteen hours after adding hydroxyl peroxide $\left(\mathrm{H}_{2} \mathrm{O}_{2}\right)$, the culture medium was replaced with MTT solution $(0.5 \mathrm{mg} / \mathrm{ml}, 250 \mu \mathrm{l})$, and the MTT incubation was continued for $1.5 \mathrm{~h}$ at $37^{\circ} \mathrm{C}$. Then $250 \mu \mathrm{l}$ of lysis buffer including acidified isopropyl alcohol was added to dissolve the formazan product. Absorbance was measured with a scanning multi-well plate reader at a wavelength of $550 \mathrm{~nm}$ (BioRad Laboratories Inc., Hercules, CA, USA) after agitating the 
plates. All experiments were performed using 3-4 separate cultures to confirm reproducibility. Cell viability was expressed as a percentage of non-treated control.

\subsection{Western blot analysis}

Western immunoblotting was carried out as reported previously (Numakawa et al., 2009). Prior to the assay, protein concentration in lysates was measured according to the method described by Lowry et al. (1951). The same amount of the boiled samples (10-12 $\mu \mathrm{g} / \mathrm{lane})$ was subjected to 8$12 \%$ of SDS-PAGE gels and the proteins were transferred to a nitrocellulose membrane. Transferred membranes were blocked for $1 \mathrm{~h}$ in 5\% non-fat milk in TBS. Primary antibodies were incubated overnight at $4^{0} \mathrm{C}$ at the following dilutions: anti-Akt $(1: 1000$, Cell Signaling Technology, Inc., MA), anti-pAkt (1:1000, Cell Signaling Technology, Inc., MA), anti-ERK (1:1000, Cell Signaling Technology, Inc., MA), anti-pErK (1:1000, Cell Signaling Technology Inc., MA), anti-BDNF (1;250, Santa Cruz Biotechnology Inc., CA), anti-TrKB(1:1000, BD Biosciences), anti-bFGF (1:2000, Santa Cruz Biotechnology), anti-Bcl-2 (1:1000, BD Bioscience), anti-pShp2 (1:1000, Cell Signaling Technology Inc., MA), and anti-Shp2 (1:2500, BD Transduction Laboratories), and anti- $\beta$-actin (1:1500, Sigma) antibodies. Then the blots were washed three times for 10 min each with $10 \mathrm{ml}$ TBS and incubated with secondary antibody in 10 $\mathrm{ml}$ blocking buffer (1:2000), with gentle agitation for $1 \mathrm{~h}$ at room temperature. The blots were then washed two times for $10 \mathrm{~min}$ each in TBS, exposed to ECL reagent for $1 \mathrm{~min}$, and developed. Bands were analyzed using Lane \& Spot Analyzer software (ATTO Corporation, Tokyo, Japan). The changes in protein expression are presented as a ratio that normalized to a level of control in each experiment. 


\subsection{Behavioral experiments}

\subsubsection{Animals}

The work was conducted in accordance with the European Communities Council Directive of 24 November 1986 (86/609/) and the National Act on the use of Experimental Animals (Germany). The experimental protocol for part of this study was approved by the Ethics Commission of the Federal State of Saxony-Anhalt, Germany. All efforts were made to minimize the number of mice used and their suffering.

For the behavioral experiments, male C57B1/6Rj mice (Janvier Labs, Saint-Berthevin Cedex, France) were kept under controlled laboratory conditions with a light/dark cycle of 12:12 (lights on at 6.00 a.m.), temperature $20 \pm 2{ }^{\circ} \mathrm{C}$, and air humidity between 55 and $60 \%$. The animals had free access to commercial pellets (ssniff R/M-H, ssniff Spezialdiäten GmbH, Soest, Germany) and tap water. The animals were housed in groups of 10 in Macrolon III cages. After arrival, the animals were allotted a 2-week period for habituation. When the experiments began, the mice were 8 weeks old.

\subsubsection{Tail suspension test (TST)}

The total duration of immobility induced by tail suspension was measured in accordance with the methods of Steru et al. (1985). Mice were suspended $30 \mathrm{~cm}$ above the floor with a stuffed clip placed approximately $1 \mathrm{~cm}$ from the tip of the tail. The duration of immobility was recorded manually over a period of 6 min. Mice were considered immobile only when they hung passively and were completely motionless. The observer was in the room where the experiments were performed, and was blind to the condition of the animal. 
Following the TST, body core temperature (BCT) was measured with a digital thermometer (ama digit) manufactured by Amarell $\mathrm{GmbH}$ (Kreuzwertheim, Germany); the lubricated probe (diameter $1 \mathrm{~mm}$ ) was gently inserted $3 \mathrm{~cm}$ into the rectum. All behavioral tests were performed in the light period between 8.00 a.m. and 2.00 p.m.

\subsubsection{Drug treatment}

The animals were randomly assigned for testing. Subsets of animals were treated intraperitoneally (injection volume $10 \mathrm{ml} / \mathrm{kg} \mathrm{bw}$ ) with $\mathrm{AC}$ extract (100 or $200 \mathrm{mg} / \mathrm{kg}$ ), with the antidepressant imipramine (Imi, $30 \mathrm{mg} / \mathrm{kg}$ ) as a standard, or with the solvent, i.e. $0.9 \%$ saline. The tests were carried out $1 \mathrm{~h}$ post application to investigate the acute substance effects. In a second group of animals, the drug effects were investigated after chronic application in accordance with the same treatment schedule as in the acute experiment, i.e. once per day for 14 days and testing $1 \mathrm{~h}$ after the last injection. In this experiment, we omitted the standard imipramine.

\subsubsection{Permanent middle cerebral artery occlusion}

Animals which were subchronically treated with AC extract were subjected to permanent middle cerebral artery occlusion 30 min after TST. Three animals were used from each group.

Permanent middle cerebral artery occlusion (MCAO) or sham surgery was performed according to Kolodziej et al. (2008). In brief, after anesthesia by intraperitoneal injection of tribromoethanol (600 mgkg), the Musculus temporalis was exposed and split. A hole was drilled into the skull to expose the middle cerebral artery. The stem of the middle cerebral artery and both branches were permanently occluded by electrocoagulation. In the case of sham surgery, the middle cerebral artery was manipulated but electrocoagulation was omitted. During surgery, body temperature was maintained at $37 \pm 0.5{ }^{\circ} \mathrm{C}$ with a heating pad connected to a control unit constantly 
measuring rectal body temperature. After MCAO, the skin was closed with tissue adhesive (Histoacryl ${ }^{\circledR}$, B. Braun Surgical, Rubi, Spain) and the mice were kept at an ambient temperature of $30{ }^{\circ} \mathrm{C}$ for $2 \mathrm{~h}$, during which time the body temperature $\left(37 \pm 0.5^{\circ} \mathrm{C}\right)$ was permanently monitored. Mice were then housed individually under controlled laboratory conditions as described above.

Twenty-four hours after MCAO, the animals were deeply anesthetized with $350 \mathrm{mg} / \mathrm{kg}$ chloral hydrate (injection volume $10 \mathrm{ml} / \mathrm{kg} \mathrm{bw}$ ), then perfused transcardially with paraformaldehyde (4\% in phosphate buffer, $\mathrm{pH}$ 7.2). The brains were removed, postfixed overnight at $4{ }^{\circ} \mathrm{C}$ in the same fixative, and cryoprotected in phosphate-buffered 30\% sucrose. Frontal cryostat sections were cut at a thickness of $20 \mu \mathrm{m}$ and stained with Cresyl violet. A light microscope was used to examine and quantify the lesion (at the level of the $3^{\text {rd }}$ ventricle) and hippocampus (at the level of the habenula).

\subsection{Statistical analysis}

The data shown in this study are expressed as mean \pm standard deviation (SD). Statistical significance was evaluated with one-way ANOVA, followed by the Newman-Keuls test for multiple groups, or the Bonferroni test. Probability values of less than 5\% were judged significant.

\section{Results}

\subsection{Methanol extract from Asparagus cochinchinensis protects against peroxide-induced neuronal cell death}

To assess the protective effect of the methanol extract of $\mathrm{AC}$ against $\mathrm{H}_{2} \mathrm{O}_{2}$-induced neurotoxicity, neurons were pre-treated with the methanol extracts $(0.01,0.1,0.5,1 \mathrm{mM})$ for $6 \mathrm{~h}$. In order to 
avoid direct reaction of $\mathrm{H}_{2} \mathrm{O}_{2}$ with $\mathrm{AC}$, prior to the addition of $\mathrm{H}_{2} \mathrm{O}_{2}(100 \mu \mathrm{M})$ the medium was replaced with fresh medium. Cell survival was assessed by measuring Formasan in the cell medium. We found that methanol extract of AC dose-dependently inhibited the neuronal damage induced by $\mathrm{H}_{2} \mathrm{O}_{2}$ (Fig. 2). The most effective concentration was observed at $1 \mathrm{mM}$.

\subsection{Modulation of Akt and ErK1/2 phosphorylation by the methanol extract from Asparagus cochinchinensis}

In order to determine the mechanism of action, we examined the effect of the methanol $\mathrm{AC}$ extract on the MAPK/ErK and PI3K intracellular signaling pathways. To test this effect, primary cultures of cortical neurons were incubated with the vehicle and methanol extract from AC (1 $\mathrm{mM}$ ) for between $5 \mathrm{~min}$ and $6 \mathrm{~h}$. We found that the methanol extract increased the phosphorylation of both ErK1/2 and Akt levels in a time-dependent manner (Fig. 3A), which suggests that AC extract activates ErK1/2 and Akt pathways. The activation of pAkt and pErK1/2 was rapid and was noted at $5 \mathrm{~min}$; it peaked at between $5 \min$ and $1 \mathrm{~h}$, and then declined after $1 \mathrm{~h}$ of treatment with AC. To confirm the involvement of MAPK/ErK and PI3K/Akt signaling pathways, we examined the effects of U0126 (a specific inhibitor of MEK, an upstream molecule of MAPK/ErK) and LY294002 (PI3K inhibitor) on the neuroprotection of AC (Fig. 3B). Cortical cultures were incubated with AC for $6 \mathrm{~h}$, with $10 \mu \mathrm{M}$ of inhibitors for 20 min after which the medium was replaced with fresh medium which did not contain AC or inhibitors. Then $100 \mu \mathrm{M}$ $\mathrm{H}_{2} \mathrm{O}_{2}$ was applied to the cultures with fresh cell medium which did not contain AC or inhibitors. Fifteen hours after stimulation with $\mathrm{H}_{2} \mathrm{O}_{2}$, we performed the MTT assay to ascertain the survival of the cultured neurons. We observed a similar degree of neuroprotection after medium change (Fig3B) as before. Fig 3B shows that both LY 294003 and U0126 inhibitors significantly blocked the protective effect of the methanol extract, thereby demonstrating the efficacy of requiring both MAPK and PI3K pathways to be used for the survival-promoting effects of methanol extract from $\mathrm{AC}$. 


\subsection{The methanol extract from Asparagus cochinchinensis stimulated the Shp-2/pShp-2 pathway}

The finding that methanol extract from AC induced increased phosphorylation of both ErK and Akt, which are signaling proteins downstream of Shp-2 (Oh et al., 1999), led us to hypothesize that Shp-2 may be involved in the protective mechanisms of the extract. To test this hypothesis, cortical neurons were incubated with the vehicle and AC $(1 \mathrm{mM})$ for between 5 min and $6 \mathrm{~h}$. As shown in Fig. 4A, AC increased the phosphorylation of Shp-2; this effect was rapid, and was observed at 5 min. The increased phosphorylation of Shp-2 persisted for 6 h (Fig. 4A), implying that methanol extract of AC markedly up-regulates the Shp-2 pathway.

To examine the involvement of Shp-2 in the protective effect of methanol extract, NSC87877, a Shp-2 signaling inhibitor, was co-applied with AC in the MTT assay (Fig. 5). Cortical cultures were incubated with $50 \mu \mathrm{M}$ of NSC 87877 inhibitor for 20 min and with AC for $6 \mathrm{~h}$ after which the medium was replaced with fresh medium which did not contain AC or NSC87877. Then 100 $\mu \mathrm{M} \mathrm{H} \mathrm{H}_{2} \mathrm{O}_{2}$ was applied to the cultures with the fresh medium. As shown in Fig. 3B, NSC87877 inhibitor blocked the AC-induced promotion of the survival effect, thereby confirming the involvement of the Shp-2 pathway in the protective effect of AC.

We also asked whether AC-induced up-regulation of pShp-2 is required for the activation of ErK1/2 and PI3K/Akt pathways. To address this question, cortical neurons were incubated with

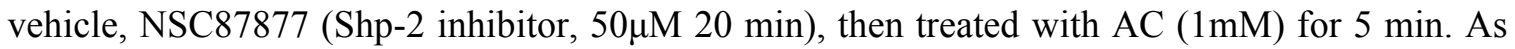
shown in Fig. 4B, pretreatment with NSC87877 reduced AC-induced activation of pShp-2 and pErK1/2 levels, indicating that activation of these signaling pathways was mediated by the Shp-2 signaling pathway. On the other hand, NSC87877 did not inhibit AC-mediated activation of pAkt, indicating that $\mathrm{AC}$ activates the pAkt pathway via an independent mechanism unrelated to the Shp2 signaling pathway (Fig. 4B). 


\subsection{Other protein modulation by total saponins from Asparagus cochinchinensis}

There is evidence that saponins exerted a neuroprotective effect by inducing ErK1/2 pathway signaling mediated by GR activation (Wu et al., 2012). Thus we hypothesized that AC can induce the activation of GR and MR proteins as a saponin-rich medicinal plant. The results revealed that methanol extract of AC induced activation of GR at $1 \mathrm{~h}$ and remained stable for $3 \mathrm{~h}$ (Fig. 6) while the levels of MR protein were not changed.

Next, we examined the effect of $\mathrm{AC}$ on the activation of BDNF protein. BDNF plays a fundamental role in supporting survival and regulates neuronal function through the MAPK and PI3K pathways (Sun et al., 2008). There were no obvious effects on the protein over $6 \mathrm{~h}$ (Fig 7). We also tested the modulation of Bcl-2 by the methanol extract, which is the survival molecule. The methanol extract did not influence the level of Bcl2 protein. However, we observed that the bFGF level was enhanced by AC at $6 \mathrm{~h}$ after treatment (Fig. 7), indicating a possible involvement of the bFGF pathway in the protective action of AC. bFGF promotes the survival of neurons (Walicke et al., 1986; Freese et al., 1992).

\subsection{Tail suspension test}

\subsubsection{Asparagus cochinchinensis extract after acute administration}

In comparison with saline-injected control groups, the standard antidepressant Imi, when administered in a dose of $30 \mathrm{mg} / \mathrm{kg}$, significantly reduced immobility time $\left(\mathrm{F}_{2,17}=17.41, \mathrm{p}=\right.$ 0.002), thus demonstrating the validity of our model (Fig. 8).

Compared with saline, there was a significant effect of $A C$ extract $\left(F_{1,10}=4.1, p=0.035\right)$. Post hoc analysis revealed no effect of $100 \mathrm{mg} / \mathrm{kg}$ extract $(\mathrm{p}=0.7)$, whereas $200 \mathrm{mg} / \mathrm{kg}$ significantly reduced immobility time $(\mathrm{p}=0.034)$. 
Acute Imi reduced body temperature $\left(\mathrm{F}_{1,10}=5.34, \mathrm{p}=0.043\right)$ whereas AC extract had no effect $\left(\mathrm{F}_{2,17}=2.21, \mathrm{p}=0.14\right)$ (Fig. 9).

\subsubsection{Asparagus cochinchinensis extract effects after subchronic administration}

After subchronic treatment, the immobility time was significantly different $\left(\mathrm{F}_{2,21}=14.1, \mathrm{p}<\right.$ 0.0001). Compared with saline-injected controls, immobility time was reduced in animals treated with $100 \mathrm{mg} / \mathrm{kg}(\mathrm{p}=0.002)$ and $200 \mathrm{mg} / \mathrm{kg}(\mathrm{p}<0.001)$ respectively (Fig. 8).

Chronic treatment with $\mathrm{AC}$ extract did not change body temperature $\left(\mathrm{F}_{2,21}=2.7, \mathrm{p}=0.06\right)($ Fig. 9).

\subsection{Asparagus cochinchinensis extract effect on infarct size}

In a pilot study, we measured the effect of subchronically-administered AC extract on infarct size after MCAO. Infarct size in the selected slices is lower in the hippocampus (control $125.9 \pm 8.7$ $\mu \mathrm{m}^{3}, \mathrm{AC} 55.9 \pm 22.6 \mu \mathrm{m}^{3}$ ) and striatum (control $53.8 \pm 13.7 \mu \mathrm{m}^{3}, \mathrm{AC} 19.7 \pm 14.5 \mu \mathrm{m}^{3}$ ) in the animals pretreated with AC.

\section{Discussion}

In the present study, we observed a neuroprotective effect of $\mathrm{AC}$ against oxidative stress induced by $\mathrm{H}_{2} \mathrm{O}_{2}$ in a dose-dependent manner (Fig. 2). To clarify the molecular mechanism of neuroprotection, the effect of methanol extract from AC on both PI3-K/Akt and MAPK/ErK1/2 intracellular signaling pathways was analyzed. These pathways are well known as a cellular survival signaling system (Jantas et al., 2014). AC induced a rapid activation of both ErK1/2 and Akt signaling pathways at a concentration of $1 \mathrm{mM}$. As shown, $\mathrm{AC}$ induced activation of $\mathrm{pErK} 1 / 2$ 
and pAkt for $1 \mathrm{~h}$ and declined after $1 \mathrm{~h}$ incubation (Fig. 3A). In our system, cells were never simultaneously incubated with $\mathrm{AC}$ and $\mathrm{H}_{2} \mathrm{O}_{2}$ excluding the possibility of the protective effect as shown in Fig. 3B being due to radical scavenging in the petri dish. Consistently with these results of pathway activation analysis, the inhibitors U0126 and LY294002 attenuated the protective effect of $\mathrm{AC}$ against $\mathrm{H}_{2} \mathrm{O}_{2}$-induced cell death, which confirmed the involvement of these pathways in the neuroprotective mechanism of AC. Such stimulation of ErK1/2 and Akt activation may result from the ability of AC to stimulate upstream pathways. For example, Ras/Raf is upstream of both (MAPK)/ErK and (PI3K)/Akt signaling pathways (Kolch, 2000; Xue et al., 2000). Ras promotes neuronal survival, activating the PI3K (Khwaja et al., 1997) or MAPK (Ballif and Blenis, 2001). A large body of evidence has demonstrated that phytochemical saponins modulate both ErK1/2 and AkT signaling pathways in a variety of ways (Ellington et al., 2006). Similarly, Ginsenoside-Rg1 induces the activation of the pAkt signaling pathway (Leung et al., 2011).

In our search for the mechanisms underlying the neuroprotective effect, we observed that $\mathrm{AC}$ increased the level of bFGF at $6 \mathrm{~h}$ after pre-treatment (Fig. 7). This indicates a possible involvement of bFGF in the protective effect of AC. bFGF rapidly regulates neuronal function through the MAPK pathway (Numakawa et al., 2009). The survival effects of neurotrophic factors mediated via the intracellular signaling cascades include PI3k and ErK (Ishikawa et al., 2000; Yamagishi et al., 2003). For example, BDNF protects against glutamate-induced cell death through the MAPK/ERK and PI3K pathways (Almeida et al., 2005). Treatment with AC did not result in any change in the levels of BDNF and TrKB receptor over $6 \mathrm{~h}$. However, it did not affect the level of Bcl-2 protein over $6 \mathrm{~h}$. Yet many studies have documented that Bcl-2 protein plays a crucial role in protecting against oxidative stress-induced cell death (Hockenbery et al., 1993; Kane et al., 1995). Phytochemical saponins are reported to have a neuroprotective effect due to up-regulation of GR mediated by MAPK (Wu et al., 2012). Thus we hypothesized that AC can induce activation of GR protein as a saponin-rich medicinal plant. The results showed that 
methanol extract of AC induced activation of GR, peaking at $1 \mathrm{~h}$ and remaining stable for $5 \mathrm{~h}$ (Fig. 6).

There is considerable evidence that Shp-2 activates MAPK/ErK1/2 and PI3K/Akt signaling pathways (Yart et al., 2001). The protein-tyrosine phosphate Shp-2 plays an essential role in cell proliferation, differentiation, and cell protection functions (Rusanescu et al., 2005). Recently, we found that NSC87877, a Shp-2 inhibitor, decreased the activation of ErK1/2 in cultured cortical neurons (Kumamaru et al., 2011). Our previous study has shown that an extract of Iris tenuifolia activated the phosphorylation of Shp-2, demonstrating a neuroprotective effect (Aldarmaa et al, 2014). These observations underline that Shp-2 plays an important role in the protection mechanism in cells (Wang et al., 2012), and led us to test the potential involvement of Shp-2 in the protective effect of AC. We found that AC stimulated the phosphorylation of Shp-2 over the 6 hours following pre-treatment. The highest degree of activation was observed at $5 \mathrm{~min}$ and persisted for $6 \mathrm{~h}$ (Fig. 4A), demonstrating a marked up-regulation of the Shp-2 signaling pathway. Consistently with this, the protective effect of $\mathrm{AC}$ was significantly blocked by NSC87877 (Fig. 5) strongly suggesting that the Shp-2 pathway played a part in the protective effect of AC. Moreover, our results indicated that AC-induced up-regulation of pShp-2 is required for the activation of the ErK1/2 signaling pathway. As shown Fig. 4B, NSC87877 attenuated the increased $\mathrm{pErK} 1 / 2$ level, whereas this inhibitor failed to change the level of the pAkt signaling pathway. These findings demonstrate that AC promoted survival under oxidative stress by directly inducing the activation of intracellular signaling Shp-2 mediating through the MAPK/ErK1/2 pathway and exhibiting additional up-regulation of the PI3-K/Akt signaling pathway.

As shown in Fig. 2, the methanol extract of AC dose-dependently inhibited the neuronal damage induced by $\mathrm{H}_{2} \mathrm{O}_{2}$. The MTT assay is a general assay for cell viability and proliferation. In the moment we cannot exclude $\mathrm{AC}$ effects on proliferation and therefore the result should be interpreted with some caution. 
Rats undergoing long-term corticosterone treatment showed decreased phosphorylation of ErK1/2 in the hippocampus, suggesting a possible role of ErK1/ErK2 in stress and depression (Gourley et al., 2008; Gai et al., 2014; Leem et al., 2014; Wang et al., 2014). Moreover, Shp-2 was found to play an important role in microglial activation. It was speculated that this pathway may have implications for the treatment of several neurodegenerative diseases, including Parkinson's disease, stroke, and Alzheimer's disease (Kim et al., 2002). As shown in our experiments (Fig. 8), after acute administration $\mathrm{AC}$ reduced immobility time as an equivalent of antidepressant-like activity at the higher dose, whereas after subchronic treatment both doses significantly reduced immobility time. This is consistent with other reports showing that Imi normalizes the derangement of ERK/Creb coupling (Yasuda et al., 2014). ErK1 and ErK2 are abundant in the hippocampus, a region of the brain which is involved in stress responses and depression (Chen et al., 2001; McLaughlin et al., 2007). It was reported that mood stabilizers stimulate the ERK pathway at therapeutic concentrations, in a clinically-relevant time frame, and in brain regions associated with mood modulation, and conversely that inhibiting the ERK pathway produces behavioral effects in rats that are normalized by mood stabilizer treatment (Einat et al., 2003). Thermoregulation is often altered in affective disorders such as depression and antidepressant drugs are also associated with alterations of body temperature. As shown in Fig. 9, acute Imi resulted in hypothermia whereas acute and subchronic treatment with AC did not result in changes in body temperature. It was suggested that $\alpha_{2}$ adrenoceptor (Zarrindast et al., 2003) and 5- $\mathrm{HT}_{1 \mathrm{~A}}$ receptor (Wozniak et al., 1989) are involved in Imi hypothermic responses. Interestingly AC did not induce hypothermia in doses which had antidepressant-like effects (Fig. 8) which suggests a different mode of action and, moreover a superior side effect profile.

In conclusion, our results show that methanol extract from Asparagus cochinchinensis exerts a neuroprotective effect against oxidative stress, exerts antidepressive-like effects, and reduces infarct size after permanent MCAO. These effects appear to be associated with activation of the Shp-2, ErK1/2 and Akt signaling pathways. Our findings indicate that there is a direct correlation between $\mathrm{AC}$-induced activation of $\mathrm{pShp}-2$ and $\mathrm{pErK} 1 / 2$ pathways. 


\section{Competing financial interests}

The authors declare no competing financial interests.

\section{Acknowledgement}

We are grateful to the Institute of Traditional Medicine and Technology, Mongolia for the supply of Asparagus cochinchinensis which was critical to this study. This study was supported by a grant from the Ministry of Education, Culture, and Science, Mongolia (J.A), an Intramural Research Grant (24-11) for Neurological and Psychiatric Disorders from the NCNP (H.K., J.A), and the Core Research for Evolutional Science and Technology Program (CREST) of the Japan Science and Technology Agency (JST) (T.N. and H.K.). We gratefully acknowledge the expert assistance of Ms. P. Dehmel, K. Schäfer, and D Trzeczak. 
Legends

Figure 1 Structure of Asparagus cochinchinensis saponin

Figure 2 Protective effect of the extract of Asparagus cochinchinensis (AC). Above: experimental schedule. Neurons (DIV3) were treated with different concentrations of total saponins $(0.01,0.1,0.5,1 \mathrm{mM})$ following $6 \mathrm{~h}$ incubation. The vehicle (100mM DMSO) was added to the cultures untreated with total saponins. Afterward, the cultures were exposed to $\mathrm{H}_{2} \mathrm{O}_{2}$ $(100 \mu \mathrm{M})$ for $15 \mathrm{~h}$ (black bars). Below: cell survival was determined with the MTT assay. Results are expressed as a percentage of neuronal cell death relative to untreated cells, and each column represents mean \pm SEM. ( $n=6, n$ indicates the number of wells for each experimental condition). ${ }^{\#} \mathrm{p}<0.001$ vs. $+\mathrm{H}_{2} \mathrm{O}_{2}$. *** $\mathrm{p}<0.001 ; * * \mathrm{P}<0.01 ; * \mathrm{P}<0.05$ indicate a significant increase in cortical neuron viability relative to $\mathrm{H}_{2} \mathrm{O}_{2}$-treated neurons.

Figure 3A Treatment with methanol extract from Asparagus cochinchinensis (AC) activated both the MAPK and the PI3K pathways. (pAkt). Time course of the activation of the PI3K pathway, (pErK1/2) time course of the activation of the MAPK pathway after exposure to the extract from AC $(1 \mathrm{mM})$. Cortical neurons were exposed over an increasing length of time to the extract from AC (1mM). The extract was applied at DIV4 and the cultures were incubated for $0.12,1,3$, and 6 h. Afterward, the cell lysates were collected. $0 \mathrm{~h}$ means non-application of total saponins. The levels of Akt (a component of the PI3K pathway), phosphorylated Akt (pAkt), and dually phosphorylated ErK1/2 (pErk1/2) were measured by immunoblotting (a). Band intensities for Akt and ErK1/2 blots were determined by densitometric analysis using BioRad Quantity One 1-D analysis (b). The data represent mean $\pm \operatorname{SEM}\left(\mathrm{n}=9\right.$, from 7 independent cultures). ${ }^{\# \#} \mathrm{p}<0.001$ band of ErK2 vs. $0 \mathrm{~h}$; $* * * \mathrm{p}<0.001, * * \mathrm{p}<0.01$ vs. $0 \mathrm{~h}$ : indicate significant increases in phosphorylation of ErK1/2 or AkT relative to vehicle-treated cells. 
Figure 3B MAPK and PI3K pathways were involved in the protective effect against neuronal cell death of the extract from Asparagus cochinchinensis (AC). The effects of LY294002 (PI3K inhibitor) and U0126 (specific inhibitor of MEK) on survival dependent on total saponins. At DIV4, LY294002 $(10 \mu \mathrm{M})$ or U0126 $(10 \mu \mathrm{M})$ was added $20 \mathrm{~min}$ before adding total saponins $(1 \mathrm{mM}$, respectively) or their vehicle (100mM DMSO), and the cultures were incubated with total saponins for $6 \mathrm{~h}$ in the presence and absence of these inhibitors. $\mathrm{H}_{2} \mathrm{O}_{2}(100 \mu \mathrm{M})$ was subsequently applied for $15 \mathrm{~h}$. MTT assay. The data represent mean $\pm \operatorname{SEM}(\mathrm{n}=6) .{ }^{\#} \mathrm{p}<0.001$ indicates a significant increase in cortical neuron viability relative to $\mathrm{H}_{2} \mathrm{O}_{2}$-treated neurons. ${ }^{* * *} \mathrm{p}<0.001$ vs. + the extract $\mathrm{AC}+\mathrm{H}_{2} \mathrm{O}_{2}$ indicates a significant increase relative to $\mathrm{H}_{2} \mathrm{O}_{2}$-treated neurons; *** $\mathrm{p}<$ $0.001(\mathrm{U} 0126), * * * \mathrm{p}<0.001(\mathrm{LY} 294002)$ vs. + total saponins, $+\mathrm{H}_{2} \mathrm{O}_{2}$ indicates a significant decrease relative to saponins-treated neurons.

Figure 4 A The extract from Asparagus cochinchinensis (AC) modulated pShp2 and total Shp-2 signaling. Band intensities for pShp-2 and total Shp-2 in cortical neurons (DIV4) exposed to total saponins (1mM) (black bar) after 5 min, $1 \mathrm{~h}, 3 \mathrm{~h}$, and $6 \mathrm{~h}$. (A) The levels of phosphorylated Shp-2 (pShp-2) and total Shp-2 were measured by immunoblotting (a). Band intensities for pShp-2, total Shp-2 and $\beta$-actin were determined by densitometric analysis using BioRad Quantity One 1-D Analysis (b). ${ }^{* * *}$ p $<0.001$ vs. $0 \mathrm{~h}, * * \mathrm{p}<0.01$ vs. $0 \mathrm{~h}$ indicates a significant increase in the pShp-2 level $(\mathrm{p}<0.001)$ relative to vehicle-treated neurons, $\mathrm{n}=5$ independent cultures.

Figure 4B The effect of NSC87877 on phosphorylated Shp-2 (pShp-2), Akt and ErK1/2 signaling pathways. Band intensities for pShp-2, pAkt and pErK1/2 in cortical neurons (DIV4) exposed to NSC87877 for 20 min, then pretreated with extract from Asparagus cochinchinensis AC (1mM) for 5 min (a). Band intensities for pShp-2 (b), pErK1/2(c), and pAkt (d) were determined by 
densitometric analysis using BioRad Quantity One 1-D Analysis. \# p $<0.05$ vs. 0 h, ${ }^{*} \mathrm{p}<0.05$, $* * \mathrm{p}<0.01, \mathrm{p}<0.001$ vs. $0 \mathrm{~h}$ indicates a significant increase in pShp-2, pAkt, pErK1/2 levels $(\mathrm{p}<0.05)$ relative to vehicle-treated neurons, $\mathrm{n}=5$ independent cultures.

Figure 5 Shp-2 signaling pathway inhibitor NSC87877 blocks total saponins-induced protection against neuronal cell death. Neuronal survival as assessed by MTT assay. Above: neurons (DIV4) were treated with $\mathrm{H}_{2} \mathrm{O}_{2}(100 \mu \mathrm{M})$ only or with $\mathrm{H}_{2} \mathrm{O}_{2}$ following $15 \mathrm{~h}$ pre-incubation with total saponins for $6 \mathrm{~h}(1 \mathrm{mM})$. Below: results are expressed as a percentage of neuronal cell death relative to untreated cells and each column represents the mean $\pm \mathrm{SEM}, \mathrm{n}=6 .{ }^{\#} \mathrm{p}<0.001$ indicates a significant increase relative to $\mathrm{H}_{2} \mathrm{O}_{2} ; * * * \mathrm{p}<0.001$ indicates a significant decrease relative to the neurons treated with an extract of $\mathrm{AC}, \mathrm{n}=6$.

Figure 6 Effect of total saponins on mineralocorticoid receptor (MR) and glucocorticoid receptor (GR) proteins. Band intensities for proteins in cortical neurons (DIV4) exposed to total saponins (1 mM, $5 \mathrm{~min}, 1 \mathrm{~h}, 3 \mathrm{~h}, 6 \mathrm{~h}$ ) (a). Band intensities were determined by densitometric analysis using BioRad Quantity One 1-D Analysis. (c). The data represent mean \pm SD of five independent experiments. The data represent mean \pm SEM of five independent cultures. ${ }^{* *} \mathrm{P}<0.01,{ }^{* * *} \mathrm{p}<$ 0.001 vs. $0 \mathrm{~h}$ indicates increases in proteins (GR and MR) relative to vehicle-treated cells.

Figure 7 Effect of total saponins on BDNF, Bcl-2 and bFGF proteins. Band intensities for proteins in cortical neurons (DIV4) exposed to total saponins (1 mM, $5 \mathrm{~min}, 1 \mathrm{~h}, 3 \mathrm{~h}, 6 \mathrm{~h}$ ) ( a). Band intensities for BDNF (b), Bcl2 (c), and bFGF (d) were determined by densitometric analysis using BioRad Quantity One 1-D Analysis.. The data represent mean \pm SEM of five independent experiments. The data represent mean $\pm \mathrm{SD}$ of five independent cultures. $* * * \mathrm{p}<0.001$ indicates increases in proteins (BDNF, Bcl-2, and bFGF) relative to vehicle-treated cells. 
Figure 8: Asparagus cochinchinensis extract (AC) and Imipramin (Imi) effects on immobility (s) in the tail suspension test. sal = saline. (a) After acute application. (b) After subchronic (14 days') treatment. Mean \pm SEM Dose $\mathrm{mg} / \mathrm{kg}$ body weight

Figure 9: Asparagus cochinchinensis extract (AC) and Imipramin (Imi) effects on body core temperature. sal = saline. (a) After acute application. (b) After subchronic (14 days') treatment. Mean \pm SEM Dose $\mathrm{mg} / \mathrm{kg}$ body weight 
References

Abel T, Zukin RS (2008) Epigenetic targets of HDAC inhibition in neurodegenerative and psychiatric disorders. Curr Opin Pharmacol 8:57-64.

Alexi T, Borlongan CV, Faull RL, Williams CE, Clark RG, Gluckman PD, Hughes PE (2000) Neuroprotective strategies for basal ganglia degeneration: Parkinson's and Huntington's diseases. Prog Neurobiol 60:409-470.

Almeida RD, Manadas BJ, Melo CV, Gomes JR, Mendes CS, Graos MM, Carvalho RF, Carvalho AP, Duarte CB (2005) Neuroprotection by BDNF against glutamate-induced apoptotic cell death is mediated by ERK and PI3-kinase pathways. Cell Death Differ 12:1329-1343.

Ballif BA, Blenis J (2001) Molecular mechanisms mediating mammalian mitogen-activated protein kinase (MAPK) kinase (MEK)-MAPK cell survival signals. Cell Growth Differ 12:397408.

Chawla A, Chawla P, Roy MRC (2011) Asparagus racemosus (Willd): Biological activities and its active principle. Indo-Global J Pharm Sciences 1:113-120.

Chen Z, Gibson TB, Robinson F, Silvestro L, Pearson G, Xu B, Wright A, Vanderbilt C, Cobb MH (2001) MAP kinases. Chem Rev 101:2449-2476.

Einat H, Yuan P, Gould TD, Li J, Du J, Zhang L, Manji HK, Chen G (2003) The role of the extracellular signal-regulated kinase signaling pathway in mood modulation. J Neurosci 23:73117316.

Ellington AA, Berhow MA, Singletary KW (2006) Inhibition of Akt signaling and enhanced ERK1/2 activity are involved in induction of macroautophagy by triterpenoid B-group soyasaponins in colon cancer cells. Carcinogenesis 27:298-306.

Freese A, Finklestein SP, DiFiglia M (1992) Basic fibroblast growth factor protects striatal neurons in vitro from NMDA-receptor mediated excitotoxicity. Brain Res 575:351-355.

Gai BM, Sanna MD, Stein AL, Zeni G, Galeotti N, Nogueira CW (2014) ERK1/2 phosphorylation is involved in the antidepressant-like action of 2,5-diphenyl-3-(4fluorophenylseleno)-selenophene in mice. Eur J Pharmacol 736:44-54. 
Gourley SL, Wu FJ, Kiraly DD, Ploski JE, Kedves AT, Duman RS, Taylor JR (2008) Regionally specific regulation of ERK MAP kinase in a model of antidepressant-sensitive chronic depression. Biol Psychiatry 63:353-359.

Halliwell B (1992a) Oxygen radicals as key mediators in neurological disease: fact or fiction? Ann Neurol 32 Suppl:S10-S15.

Halliwell B (1992b) Reactive oxygen species and the central nervous system. J Neurochem 59:1609-1623.

Halliwell B, Gutteridge JM, Cross CE (1992) Free radicals, antioxidants, and human disease: where are we now? J Lab Clin Med 119:598-620.

Hockenbery DM, Oltvai ZN, Yin XM, Milliman CL, Korsmeyer SJ (1993) Bcl-2 functions in an antioxidant pathway to prevent apoptosis. Cell 75:241-251.

Hunsberger J, Austin DR, Henter ID, Chen G (2009) The neurotrophic and neuroprotective effects of psychotropic agents. Dialogues Clin Neurosci 11:333-348.

Ishikawa Y, Ikeuchi T, Hatanaka H (2000) Brain-derived neurotrophic factor accelerates nitric oxide donor-induced apoptosis of cultured cortical neurons. J Neurochem 75:494-502.

Jantas D, Krawczyk S, Lason W (2014) The predominant protective effect of tianeptine over other antidepressants in models of neuronal apoptosis: the effect blocked by inhibitors of MAPK/ERK1/2 and PI3-K/Akt pathways. Neurotox Res 25:208-225.

Kane DJ, Ord T, Anton R, Bredesen DE (1995) Expression of bcl-2 inhibits necrotic neural cell death. J Neurosci Res 40:269-275.

Khwaja A, Rodriguez-Viciana P, Wennstrom S, Warne PH, Downward J (1997) Matrix adhesion and Ras transformation both activate a phosphoinositide 3-OH kinase and protein kinase B/Akt cellular survival pathway. EMBO J 16:2783-2793.

Kim H, Lee E, Lim T, Jung J, Lyu Y (1998) Inhibitory effect of Asparagus cochinchinensis on tumor necrosis factor-alpha secretion from astrocytes. Int J Immunopharmacol 20:153-162.

Kim OS, Park EJ, Joe EH, Jou I (2002) JAK-STAT signaling mediates gangliosides-induced inflammatory responses in brain microglial cells. J Biol Chem 277:40594-40601.

Kolch W (2000) Meaningful relationships: the regulation of the Ras/Raf/MEK/ERK pathway by protein interactions. Biochem J 351 Pt 2:289-305. 
Kolodziej A, Stumm R, Becker A, Hollt V (2008) Endogenous opioids inhibit ischemia-induced generation of immature hippocampal neurons via the mu-opioid receptor. Eur J Neurosci 27:1311-1319.

Kölsch H, Rao ML (2002) Neuroprotective effects of estradiol-17beta: implications for psychiatric disorders. Arch Womens Ment Health 5:105-110.

Konishi T, Shoji J (1979) Studies on the constituents Asparagi Radix. I. On the structures of furostanol oligosides of Asparagus cochinensis (Loureio) Merrill. Chem Pharm Bull 27:30863094.

Kumamaru E, Numakawa T, Adachi N, Kunugi H (2011) Glucocorticoid suppresses BDNFstimulated MAPK/ERK pathway via inhibiting interaction of Shp2 with TrkB. FEBS Lett 585:3224-3228.

Lee dY, Choo BK, Yoon T, Cheon MS, Lee HW, Lee AY, Kim HK (2009) Anti-inflammatory effects of Asparagus cochinchinensis extract in acute and chronic cutaneous inflammation. $J$ Ethnopharmacol 121:28-34.

Leem YH, Yoon SS, Kim YH, Jo SA (2014) Disrupted MEK/ERK signaling in the medial orbital cortex and dorsal endopiriform nuclei of the prefrontal cortex in a chronic restraint stress mouse model of depression. Neurosci Lett 580:163-168.

Leung KW, Ng HM, Tang MK, Wong CC, Wong RN, Wong AS (2011) Ginsenoside-Rg1 mediates a hypoxia-independent upregulation of hypoxia-inducible factor-1alpha to promote angiogenesis. Angiogenesis 14:515-522.

Lieberman JA (1999) Is schizophrenia a neurodegenerative disorder? A clinical and neurobiological perspective. Biol Psychiatry 46:729-739.

Lowry OH, Rosebrough NJ, Farr AL, Randall RJ (1951) Protein measurement with the folin phenol reagent. The Journal of biological chemistry 193:267-275.

Maes M, Yirmyia R, Noraberg J, Brene S, Hibbeln J, Perini G, Kubera M, Bob P, Lerer B, Maj M (2009) The inflammatory \& neurodegenerative (I\&ND) hypothesis of depression: leads for future research and new drug developments in depression. Metab Brain Dis 24:27-53.

Majid A (2014) Neuroprotection in stroke: past, present, and future. ISRN Neurol 2014:515716. 
McLaughlin KJ, Gomez JL, Baran SE, Conrad CD (2007) The effects of chronic stress on hippocampal morphology and function: an evaluation of chronic restraint paradigms. Brain Res 1161:56-64.

Michel TM, Pulschen D, Thome J (2012) The role of oxidative stress in depressive disorders. Curr Pharm Des 18:5890-5899.

Moretti A, Ferrari F, Villa RF (2014) Neuroprotection for ischaemic stroke: Current status and challenges. Pharmacol Ther.

Negi JS, Singh P, Pant GJ, Rawat MS (2011) High-performance liquid chromatography analysis of plant saponins: An update 2005-2010. Pharmacogn Rev 5:155-158.

Ng F, Berk M, Dean O, Bush AI (2008) Oxidative stress in psychiatric disorders: evidence base and therapeutic implications. Int J Neuropsychopharmacol 11:851-876.

Numakawa T, Kumamaru E, Adachi N, Yagasaki Y, Izumi A, Kunugi H (2009) Glucocorticoid receptor interaction with TrkB promotes BDNF-triggered PLC-gamma signaling for glutamate release via a glutamate transporter. Proc Natl Acad Sci U S A 106:647-652.

Odaka H, Numakawa T, Adachi N, Ooshima Y, Nakajima S, Katanuma Y, Inoue T, Kunugi H (2014) Cabergoline, dopamine D2 receptor agonist, prevents neuronal cell death under oxidative stress via reducing excitotoxicity. PLoS One 9:e99271.

Oh ES, Gu H, Saxton TM, Timms JF, Hausdorff S, Frevert EU, Kahn BB, Pawson T, Neel BG, Thomas SM (1999) Regulation of early events in integrin signaling by protein tyrosine phosphatase SHP-2. Mol Cell Biol 19:3205-3215.

Ojha R, Sahu AN, Muruganandam AV, Singh GK, Krishnamurthy S (2010) Asparagus recemosus enhances memory and protects against amnesia in rodent models. Brain Cogn 74:1-9.

Pantcheva P, Elias M, Duncan K, Borlongan CV, Tajiri N, Kaneko Y (2014) The role of DJ-1 in the oxidative stress cell death cascade after stroke. Neural Regen Res 9:1430-1433.

Park M, Cheon MS, Kim SH, Chun JM, Lee AY, Moon BC, Yoon T, Choo BK (2011) Anticancer activity of Asparagus cochinchinesis extract and fraction in HepG2 cells. J Korean Soc Appl Biol Chem 54:188-193.

Rusanescu G, Yang W, Bai A, Neel BG, Feig LA (2005) Tyrosine phosphatase SHP-2 is a mediator of activity-dependent neuronal excitotoxicity. EMBO J 24:305-314. 
Singh GK, Garabadu D, Muruganandam AV, Joshi VK, Krishnamurthy S (2009) Antidepressant activity of Asparagus racemosus in rodent models. Pharmacol Biochem Behav 91:283-290.

Steru L, Chermat R, Thierry B, Simon P (1985) The tail suspension test: a new method for screening antidepressants in mice. Psychopharmacology (Berl) 85:367-370.

Sun X, Zhou H, Luo X, Li S, Yu D, Hua J, Mu D, Mao M (2008) Neuroprotection of brainderived neurotrophic factor against hypoxic injury in vitro requires activation of extracellular signal-regulated kinase and phosphatidylinositol 3-kinase. Int J Dev Neurosci 26:363-370.

Walicke P, Cowan WM, Ueno N, Baird A, Guillemin R (1986) Fibroblast growth factor promotes survival of dissociated hippocampal neurons and enhances neurite extension. Proc Natl Acad Sci U S A 83:3012-3016.

Wang G, Jin C, Hou Y, Zhang L, Li S, Zhang L, Wu B, Li Q, Xu C, Tian Y, Zhang L (2012) Overexpression of Shp-2 attenuates apoptosis in neonatal rat cardiac myocytes through the ERK pathway. Exp Mol Pathol 93:50-55.

Wang S, Hu S, Zhang C, Qiu J, Li Y (2014) Antidepressant-like activity of Chaihu-Shugan-San aqueous extract in rats and its possible mechanism. Pharmacogn Mag 10:S50-S56.

Wozniak KM, Aulakh CS, Hill JL, Murphy DL (1989) Hyperthermia induced by m-CPP in the rat and its modification by antidepressant treatments. Psychopharmacology (Berl) 97:269-274.

Wu J, Pan Z, Wang Z, Zhu W, Shen Y, Cui R, Lin J, Yu H, Wang Q, Qian J, Yu Y, Zhu D, Lou Y (2012) Ginsenoside Rg1 protection against beta-amyloid peptide-induced neuronal apoptosis via estrogen receptor alpha and glucocorticoid receptor-dependent anti-protein nitration pathway. Neuropharmacology 63:349-361.

Xiong D, Yu LX, Yan X, Guo C, Xiong Y (2011) Effects of root and stem extracts of Asparagus cochinchinensis on biochemical indicators related to aging in the brain and liver of mice. Am $\mathrm{J}$ Chin Med 39:719-726.

Xue L, Murray JH, Tolkovsky AM (2000) The Ras/phosphatidylinositol 3-kinase and Ras/ERK pathways function as independent survival modules each of which inhibits a distinct apoptotic signaling pathway in sympathetic neurons. J Biol Chem 275:8817-8824.

Yamagishi S, Matsumoto T, Yokomaku D, Hatanaka H, Shimoke K, Yamada M, Ikeuchi T (2003) Comparison of inhibitory effects of brain-derived neurotrophic factor and insulin-like 
growth factor on low potassium-induced apoptosis and activation of p38 MAPK and c-Jun in cultured cerebellar granule neurons. Brain Res Mol Brain Res 119:184-191.

Yang YC, Huang SY, Shi JG (2002) Two new Furostanol glycosides from Asparagus cochinchinensis. Chin Chem Lett 13:1185-1188.

Yart A, Laffargue M, Mayeux P, Chretien S, Peres C, Tonks N, Roche S, Payrastre B, Chap H, Raynal P (2001) A critical role for phosphoinositide 3-kinase upstream of Gab1 and SHP2 in the activation of ras and mitogen-activated protein kinases by epidermal growth factor. J Biol Chem 276:8856-8864.

Yasuda S, Yoshida M, Yamagata H, Iwanaga Y, Suenaga H, Ishikawa K, Nakano M, Okuyama S, Furukawa Y, Furukawa S, Ishikawa T (2014) Imipramine ameliorates pain-related negative emotion via induction of brain-derived neurotrophic factor. Cell Mol Neurobiol 34:1199-1208.

Zarrindast MR, Sadeghi S, Sahebgharani M (2003) Influence of alpha-adrenoceptor agonists and antagonists on imipramine-induced hypothermia in mice. Pharmacol Toxicol 93:48-53.

Zhang HJ, Sydara K, Tan GT, Ma C, Southavong B, Soejarto DD, Pezzuto JM, Fong HH (2004) Bioactive constituents from Asparagus cochinchinensis. J Nat Prod 67:194-200.

Zhang ZJ (2004) Therapeutic effects of herbal extracts and constituents in animal models of psychiatric disorders. Life Sci 75:1659-1699. 
fig 1

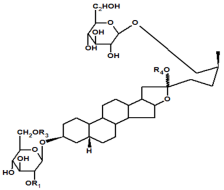


fig 2

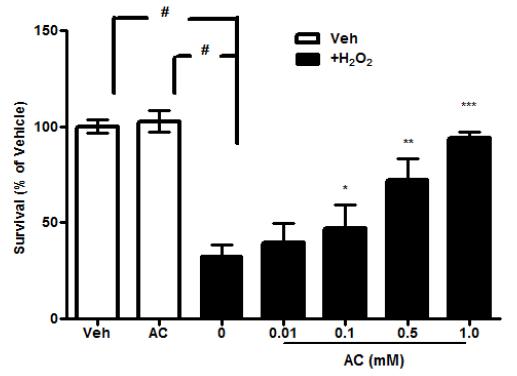


A
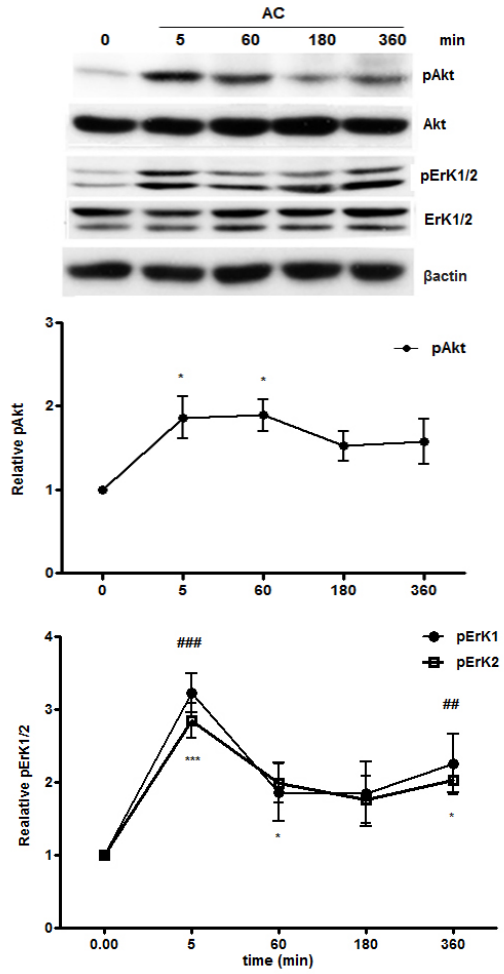
B

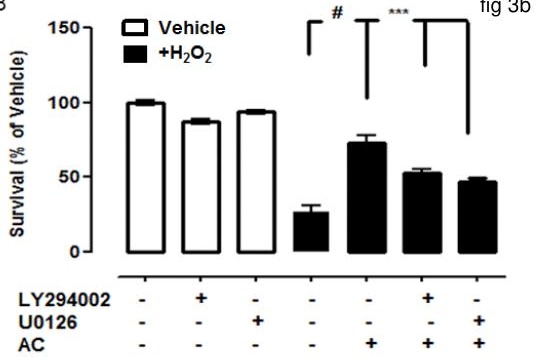


A

fig $4 a$

\begin{tabular}{lllll} 
& \multicolumn{5}{c}{ AC } \\
\cline { 2 - 5 } 0 & 5 & 60 & 180 & 360
\end{tabular}

$\min$

pShp2

Shp2

Bactin

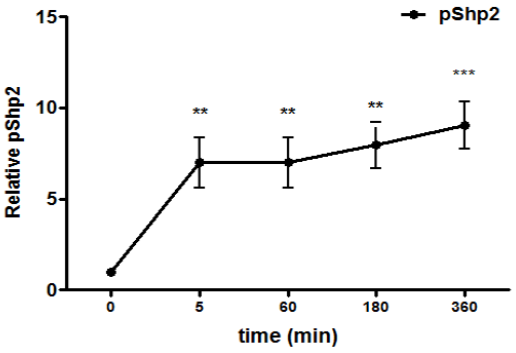




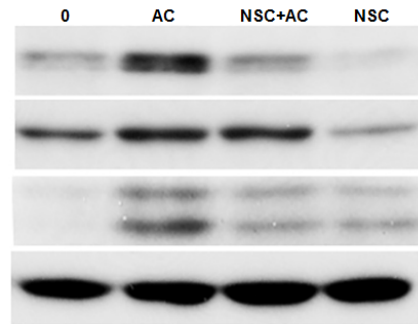

$$
\text { pShp2 }
$$

pErK1/2

Bactin
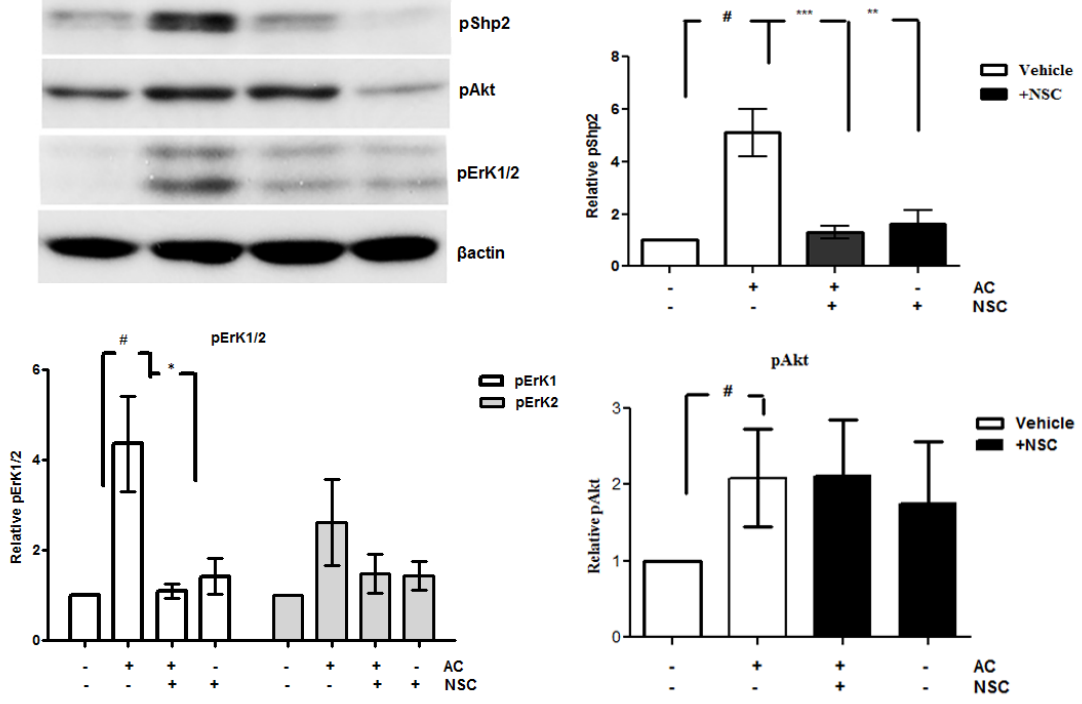
fig 6

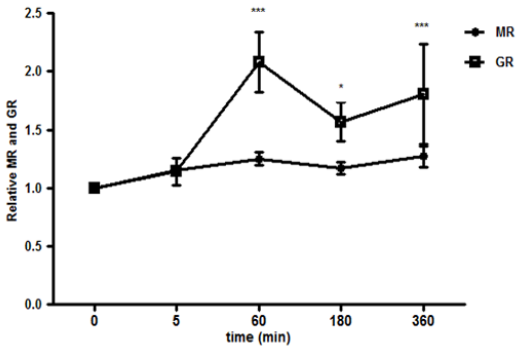


fig 7
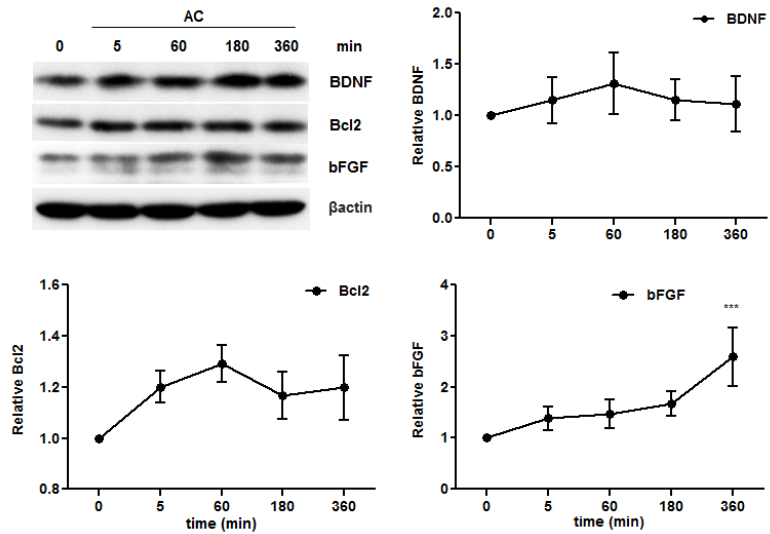
fig 8

Acute

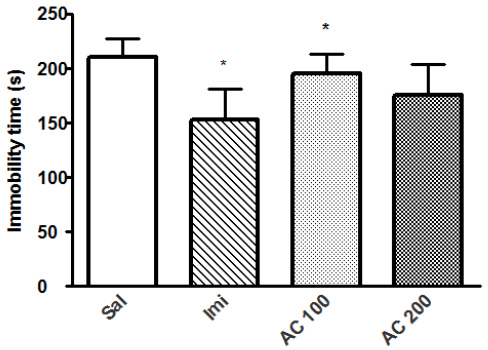

Subchronic

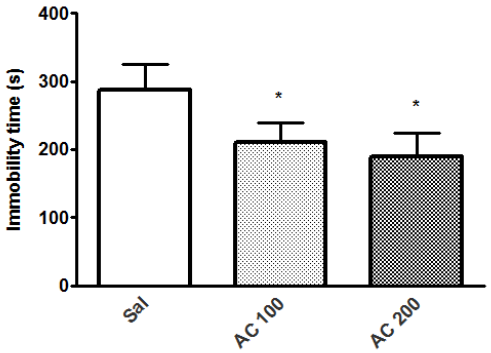


fig 9

Acute

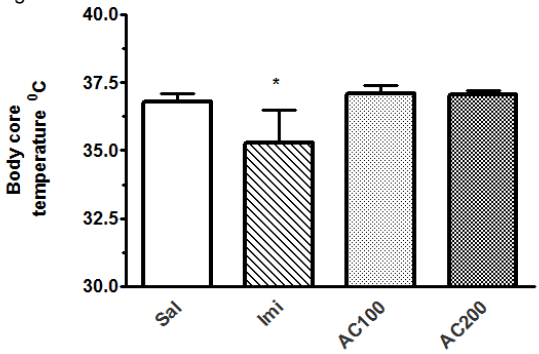

Subchronic

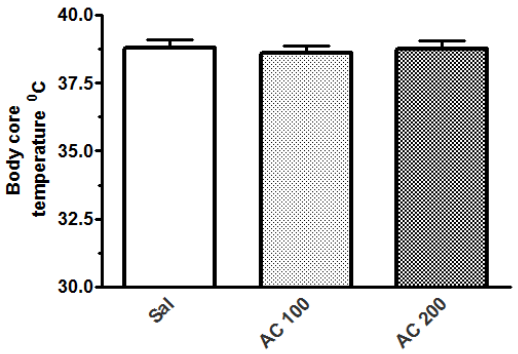

